\title{
Enhancing Astaxanthin Accumulation in Haematococcus pluvialis by Coupled Light Intensity and Nitrogen Starvation in Column Photobioreactors ${ }^{\text {S }}$
}

\author{
Wen-wen Zhang ${ }^{1}$, Xue-fei Zhou ${ }^{1}$, Ya-lei Zhang ${ }^{1}$, Peng-fei Cheng ${ }^{2}$, Rui $\mathrm{Ma}^{1}$, Wen-long Cheng', and \\ Hua-qiang $\mathrm{Chu}^{1 *}$ \\ ${ }^{1}$ State Key Laboratory of Pollution Control and Resource Reuse, Tongji University, Shanghai, 200092, P.R. China \\ ${ }^{2}$ Poyang Lake Eco-economy Research Center, Jiujiang University, Jiujiang, 332005, P.R. China
}

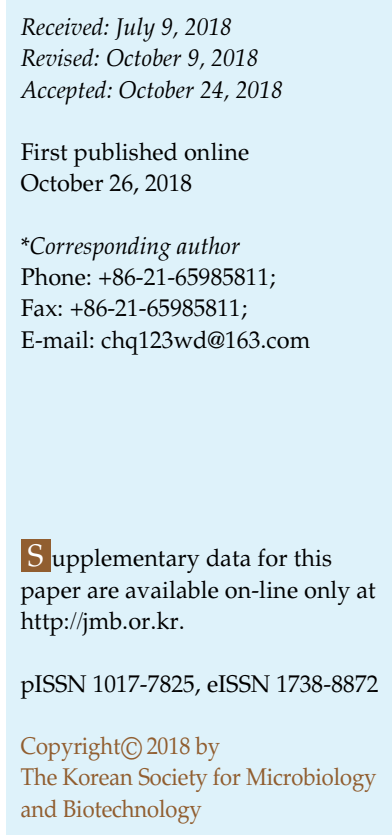

\begin{abstract}
Natural astaxanthin mainly derives from a microalgae producer, Haematococcus pluvialis. The induction of nitrogen starvation and high light intensity is particularly significant for boosting astaxanthin production. However, the different responses to light intensity and nitrogen starvation needed to be analyzed for biomass growth and astaxanthin accumulation. The results showed that the highest level of astaxanthin production was achieved in nitrogen starvation, and was 1.64 times higher than the control group at 11 days. With regard to the optimization of light intensity utilization, it was at $200 \mu \mathrm{mo} / \mathrm{m}^{2} / \mathrm{s}$ under nitrogen starvation that the highest astaxanthin productivity per light intensity was achieved. In addition, both high light intensity and a nitrogen source had significant effects on multiple indicators. For example, high light intensity had a greater significant effect than a nitrogen source on biomass dry weight, astaxanthin yield and astaxanthin productivity; in contrast, nitrogen starvation was more beneficial for enhancing astaxanthin content per dry weight biomass. The data indicate that high light intensity synergizes with nitrogen starvation to stimulate the biosynthesis of astaxanthin.
\end{abstract}

Keywords: Haematococcus pluvialis, biomass growth, astaxanthin production, high light intensity, nitrogen starvation

\section{Introduction}

Haematococcus pluvialis (H. pluvialis) has been proposed as the best natural producer for natural astaxanthin, which is widely considered a super antioxidant and a high-value product. Regarding its strength as an antioxidant, astaxanthin is 10 times more potent than other carotenoids, 54 times stronger than $\beta$-carotene, and 100 times more effective than $\alpha$-tocopherol [1-3]. Moreover, astaxanthin plays a significant role in reducing and stabilizing free radical scavenging capacity, preventing oxidization and maintaining overall health. In addition, natural astaxanthin has 20 times more antioxidant potency than its synthetic equivalent $[2,4]$ while also having a wide range of human and animal applications in the food, cosmetics, nutrition and pharmaceutical industries. This has led to an increasing demand for natural astaxanthin. H. pluvialis is regarded as the most promising microbial producer in commercial production because of its high astaxanthin content [5] and astaxanthin's great potential and high market value $[2,3]$.

H. pluvialis has become a major commercial source of natural astaxanthin, and many studies have been carried out to determine the optimal conditions for its growth and astaxanthin-producing capabilities. It has been demonstrated that $H$. pluvialis rapidly changes from the vegetative stage to the resting stage, forming aplanospores [6] and accumulating astaxanthin when exposed to various stress conditions such as high light intensity and nutrient starvation. These induction conditions were the major factors that stimulated astaxanthin accumulation. There are 
many studies where high light intensity is considered to be the main induction factor, but may also cause severe photoinhibition of photosynthesis or photo-oxidative damage of the cells $[7,8]$. Moreover, research results have indicated that during photoautotrophic induction, light intensity is more important than $\mathrm{C} / \mathrm{N}$ ratio in astaxanthin production [9]. Light intensity is indispensable to the growth of algae and is a direct method for regulation of microbial growth and biomass metabolism. However, optimum light intensity for astaxanthin accumulation has not been determined neither is it known whether to avoid excessive high or low light intensity. Besides, there are few reports concerning the differential effects on the biomass growth and astaxanthin accumulation of $H$.pluvialis in different light intensities, especially including the primary and secondary factors between high light intensity and nitrogen starvation on astaxanthin production.

This study targeted the comparative effects of different light intensities and nitrogen starvation on growth and astaxanthin accumulation, leading to increased biomass dry weight, higher astaxanthin yield and reduced cultivation costs and energy consumption. Light intensity utilization in relation to astaxanthin production in H.pluvialis subsequently was further explored. In addition, the significant differences in the effects between light intensity and nitrogen starvation were also analyzed. Our findings could provide valuable insights for higher astaxanthin production in $H$. pluvialis and to use as a guide for a future commercial market.

\section{Materials and Methods}

\section{Algal Strain and Culture Conditions}

The unicellular green algae H. pluvialis (FACHB-712) was selected as the preferred option due to its performance for high natural astaxanthin accumulation. The microalgae strain was obtained from the Institute of Hydrobiology in the Freshwater Algae Culture Collection (Chinese Academy of Sciences, China). Under sterile conditions, the microalgae cells were inoculated and cultivated in $100 \mathrm{ml}$ autoclaved Blue-Green (BG11) medium, which was the best for cultivating H.pluvialis to induce astaxanthin, and then the algae species was expanded in $250 \mathrm{ml}$, $500 \mathrm{ml}, 1,000 \mathrm{ml}$, and 2,000 ml conical flasks. The nutrient content per liter of BG11 medium was as follows: $\mathrm{NaNO}_{3}(1,500 \mathrm{mg})$, $\mathrm{K}_{2} \mathrm{HPO}_{4}(40 \mathrm{mg}), \mathrm{MgSO}_{4} \cdot 7 \mathrm{H}_{2} \mathrm{O}(75 \mathrm{mg}), \mathrm{CaCl}_{2} \cdot 2 \mathrm{H}_{2} \mathrm{O}(36 \mathrm{mg}), \mathrm{Na}_{2} \mathrm{CO}_{3}$ $(20 \mathrm{mg})$, citric acid $(6 \mathrm{mg})$, ferric ammonium citrate $(6 \mathrm{mg})$, $\operatorname{EDTANa}_{2}(1 \mathrm{mg})$, and $1 \mathrm{ml} / \mathrm{l}$ A5 (trace element solution). The A5 (in $\mathrm{g} / \mathrm{l}$ ) consisted of $\mathrm{H}_{3} \mathrm{BO}_{3}(2.86), \mathrm{MnCl}_{2} \cdot 4 \mathrm{H}_{2} \mathrm{O}(1.86), \mathrm{Na}_{2} \mathrm{MoO}_{4} \cdot 2 \mathrm{H}_{2} \mathrm{O}$ (0.39), $\mathrm{ZnSO}_{4} \cdot 7 \mathrm{H}_{2} \mathrm{O}(0.22), \mathrm{CuSO}_{4} \cdot 5 \mathrm{H}_{2} \mathrm{O}(0.08)$, and $\mathrm{Co}\left(\mathrm{NO}_{3}\right)_{2} \cdot 6 \mathrm{H}_{2} \mathrm{O}$ (0.05). The final medium was adjusted to $\mathrm{pH}$ 7.1. Nitrate was omitted from the medium for nitrogen starvation. All of the conical flasks were photoautotrophically cultured under axenic conditions and placed in a light incubator (MGC-400B, Shanghai Yiheng Scientific Instrument, China). The algal culture was irradiated with a light intensity of $50 \mu \mathrm{mol} / \mathrm{m}^{2} / \mathrm{s}$ and the light/dark ratio was $12 \mathrm{~h}: 12 \mathrm{~h}$ at $25^{\circ} \mathrm{C}$. The microalgae cells in exponential phase were collected as the inoculation for subsequent experiments.

Algal species harvested from the logarithmic growth phase were transferred to customized photobioreactors for experiments, which were carried out in glass columns of columnar photobioreactors $(1.50 \mathrm{~m}$ length $\times 0.60 \mathrm{~m}$ width $\times 1.80 \mathrm{~m}$ height $)$. The microalgae were cultivated in the columns which had the working volume of $0.7 \mathrm{~L}$ ( $5 \mathrm{~cm}$ diameter $\times 60 \mathrm{~cm}$ height)." (P5L8788) To enhance the activity of the H. pluvialis and improve the acid base environment in the cultivation process, a glass capillary (6.5 $\mathrm{mm}$ diameter $\times 65 \mathrm{~cm}$ length) was inserted into the bottom of the glass columns to supply air (containing $5 \% \mathrm{CO}_{2}, \mathrm{v} / \mathrm{v}$ ) with equal flow rate at $0.5 \mathrm{v} / \mathrm{v} / \mathrm{min}$ for every glass column. The algae cells were harvested and resuspended in a different medium in every column reactor at $20-25^{\circ} \mathrm{C}$, including the nitrogen starvation group and a control group containing a normal nitrogen source with the initial cell density of $0.3 \mathrm{~g} / 1$. The groups were then respectively cultivated for 14 days at light intensities of 50,100, 200 , and $400 \mu \mathrm{mol} / \mathrm{m}^{2} / \mathrm{s}$, forming eight different cultivation conditions. The light intensity of the photobioreactor surface was determined by the average of the light intensity values measured with an illuminance meter (model TES1332A; TES, Taiwan)." (P5L96-98) Each group was subjected to three independent treatments.

\section{Growth Analyses}

The dry weight of microalgae biomass $(\mathrm{B}, \mathrm{g} / \mathrm{l})$ was determined gravimetrically using Eq. (1), which was slightly modified referring to the report [5], where $m_{1}$ was the dry weight of the centrifuge tube, $m_{2}$ was the dry weight of the centrifuge tube with algae biomass, and $\mathrm{V}(\mathrm{V}, \mathrm{ml})$ was the volume of algae fluid samples. For dry weight measurement, the microalgae cells were centrifuged at $4^{\circ} \mathrm{C}$ for $5 \mathrm{~min}$ at $8,445 \mathrm{~g}$, washed with distilled water and then freeze-dried till constant weight.

$$
\mathrm{B}(\mathrm{g} / \mathrm{l})=\left(\mathrm{m}_{2}-\mathrm{m}_{1}\right) / \mathrm{V} / 1000
$$

The biomass productivity (BP, $\mathrm{mg} / \mathrm{l} / \mathrm{d}$ ) was calculated according to Eq. (2), where $B_{o}$ was the initial algae biomass concentration $(\mathrm{g} / \mathrm{l})$, $B_{\max }(\mathrm{g} / \mathrm{l})$ was the maximum algae biomass concentration $(\mathrm{g} / \mathrm{l})$ and $t_{R}$ was the time $(d)$ required for the algae biomass to reach $B_{\max }$.

$$
\mathrm{BP}(\mathrm{mg} / \mathrm{L} / \mathrm{d})=\frac{\mathrm{B}_{\max }-\mathrm{B}_{\mathrm{o}}}{\mathrm{t}_{\mathrm{R}}} \times 1000
$$

The maximal biomass productivity $\left(\mathrm{BP}_{\max }, \mathrm{mg} / \mathrm{l} / \mathrm{d}\right)$ between two consecutive sample points was calculated using Eq. (3), where $B_{i}, B_{i+1}(g / l)$ was the algae biomass concentration at time $t_{i}$ and $t_{i+1}(d)$. 


$$
\mathrm{BP}_{\max }(\mathrm{mg} / \mathrm{l} / \mathrm{d})=\operatorname{Max}\left[\frac{\mathrm{B}_{\mathrm{i}+1}-\mathrm{B}_{\mathrm{i}}}{\mathrm{t}_{\mathrm{i}+1}-\mathrm{t}_{\mathrm{i}}} \times 1000\right]
$$

The maximal specific growth rate $\left(\mu_{\max }, \mathrm{d}^{-1}\right)$ was obtained according to Eq. (4), and the specific growth rate between two consecutive samples was determined using Eq. (5) [10], where $B_{i}$, $B_{i+1}(g / l)$ was the algae biomass concentration at time $t_{i}$ and $t_{i+1}(d)$.

$$
\begin{aligned}
& \mu_{\max }\left(d^{-1}\right)=\operatorname{Max}\left[\frac{\ln B_{i+1}-\ln B_{i}}{t_{i+1}-t_{i}}\right] \\
& \mu\left(d^{-1}\right)=\left\lceil\frac{\ln B_{i}-\ln B_{o}}{t_{i}}\right]
\end{aligned}
$$

\section{Astaxanthin Determination}

Astaxanthin measurements were taken photometrically [11]. The harvested algae cells were collected by centrifuging at $8,445 \mathrm{~g}$ for $5 \mathrm{~min}$, first treated to destroy the chlorophyll with a solution of $5 \%(\mathrm{w} / \mathrm{v}) \mathrm{KOH}$ in $30 \%(\mathrm{v} / \mathrm{v})$ methanol at $65^{\circ} \mathrm{C}$ for $15 \mathrm{~min}$. The supernatant was abandoned, and the remaining pellet was washed three times to scour off the residual alkali which was then extracted with dimethyl sulfoxide (DMSO) to recover the astaxanthin. The extraction process was repeated until the algal cells were nearly colorless. The red supernatant was collected to measure the absorbance at $490 \mathrm{~nm}$, and the astaxanthin yield $\left(c_{\mathrm{t}}\right.$, $\mathrm{mg} / \mathrm{l}$ ) was calculated according to Eq. (6), where $\mathrm{V}_{\mathrm{a}}(\mathrm{ml})$ was the volume of extracts, $\mathrm{V}_{\mathrm{b}}(\mathrm{ml})$ was the culture sample volume, and $\mathrm{A}_{490}$ was the extract absorbance at $490 \mathrm{~nm}$.

$$
c_{t}(\mathrm{mg} / 1)=4.5 \times \mathrm{A}_{490} \times \mathrm{V}_{\mathrm{a}} \times \mathrm{V}_{\mathrm{b}}
$$

Astaxanthin content ( $\%$ dry weight, $w / w)$ was calculated using Eq. (7), where $c_{t}(\mathrm{mg} / \mathrm{l})$ was the astaxanthin yield and B $(\mathrm{mg} / \mathrm{l})$ was the dry weight of the biomass.

$$
\mathrm{C}(\%)=\mathrm{c}_{\mathrm{t}} / \mathrm{B}
$$

Astaxanthin productivity in dry weight (AP, mg/l/d) was calculated using Eq. (8)

$$
\operatorname{AP}(\mathrm{mg} / \mathrm{l} / \mathrm{d})=\frac{\mathrm{c}_{\mathrm{t}}-\mathrm{C}_{\mathrm{o}}}{\mathrm{t}} \times 1000
$$

The determination of astaxanthin productivity per light intensity was calculated using Eq. (9), where LI $\left(\mu \mathrm{mol} / \mathrm{m}^{2} / \mathrm{s}\right)$ was the specified light intensity.

Astaxanthin productivity per light intensity $\left(\mathrm{mg} / \mathrm{l} / \mathrm{d} /\left(\mathrm{mmol} / \mathrm{m}^{2} / \mathrm{s}\right)\right.$ $=\frac{\mathrm{C}_{\mathrm{t}}}{\mathrm{LI}} \times 1000$

\section{Cell Morphology}

To explore the changes in growth, the morphological changes in algal cells were observed using a metallographic positive microscope (LW300 LJT, Cewei, China), with the aim of tracking the progress of the cell morphology of $H$. pluvialis under stressed conditions. Digital images of the samples were obtained by using a CCD industrial camera, from which cell morphological changes could be statistically surveyed.

\section{Statistical Analysis}

Experiments were carried out with replicates from three separate cultures. Samples were collected from three algal replicates, and data were analyzed for the standard errors. All the data were indicated by mean \pm standard deviations (mean $\pm \mathrm{SD}$ ) and statistically analyzed by double factor variance analysis to investigate the differences among groups. $p$ value less than 0.01 $(p<0.01)$ was considered extremely significantly different, $p<0.05$ indicating statistically different, and $p$ value more than 0.05 $(p>0.05)$ was not significant.

\section{Results and Discussion}

\section{Biomass Growth}

The growth curves of $H$. pluvialis cultured under different light intensities of $50,100,200,400 \mu \mathrm{mol} / \mathrm{m}^{2} / \mathrm{s}$ with nitrogen starvation and control were generated. As shown in Fig. 1, the biomass dry weight dramatically increased with the growing light intensity, and showed almost no lag phase. The dry weight increased to $2.19 \pm 0.08$ and $3.43 \pm$ $0.06 \mathrm{~g} / 1$ under nitrogen starvation and control at the light intensity of $400 \mu \mathrm{mol} / \mathrm{m}^{2} / \mathrm{s}$, which was 1.39 times and 2.00 times higher than that at $50 \mu \mathrm{mol} / \mathrm{m}^{2} / \mathrm{s}$. The results indicated that different light intensities apparently enhanced the biomass of algal cells, which is implied in the microalgal reports [12-14], and the increase of dry weight importantly depends on the net photosynthetic production [15]. Although the growth under nitrogen starvation was far slower than that in control, leading to the lower biomass, $H$. pluvialis reached stable growth at $200,400 \mu \mathrm{mol} / \mathrm{m}^{2} / \mathrm{s}$ after 11 days. Finally, the algal dry weight was only $2.11 \pm$ 0.10 and $2.14 \pm 0.14 \mathrm{~g} / 1$ under nitrogen starvation. However, the dry weight reached $2.85 \pm 0.10$ and $3.47 \pm 0.10 \mathrm{~g} / 1$ in control group, which was $26 \%$ and $37 \%$ higher than that in nitrogen starvation. These data indicated that nitrogen starvation inhibited the growth of algae compared with control group, which is consistent with the results in the literature [16, 17]." (P8L166-168) Indeed, these effects of nitrogen starvation on biomass are similar to those parameters presented by cell density [13, 18]. Sufficient nutrient condition usually leads to higher biomass production. It indicated that nitrogen starvation reduced growth compared to the controls. This growth may be related to an increase in cell size, rather than cell division. That might be due to the lack of nutrients in cell growth 

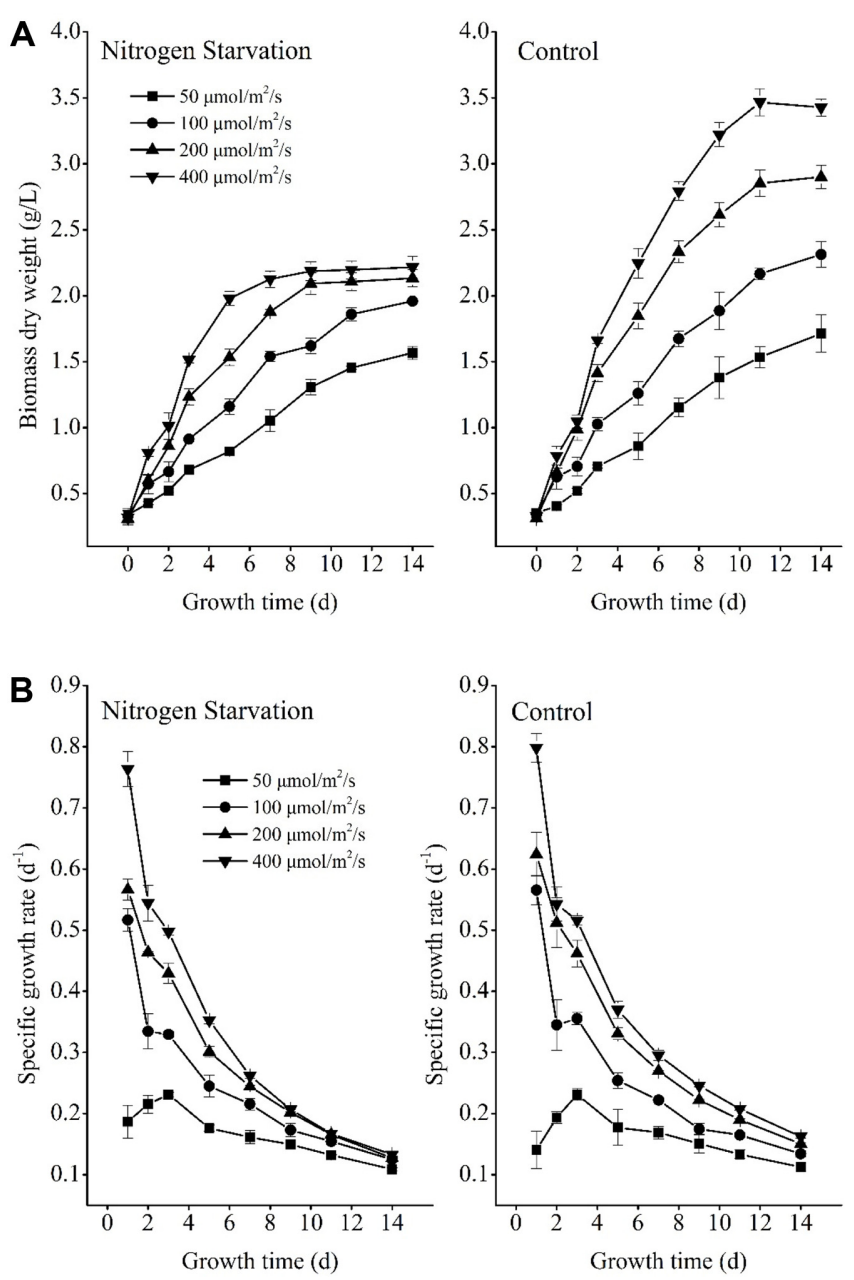

Fig. 1. Effects of different light intensities on biomass dry weight between Nitrogen Starvation and Control: biomass dry weight (A), specific growth rate (B).

and enzymatic activity of microalgae in the nitrogenstarved condition, which has been observed in several algae species [17, 19-23]. Although nitrogen starvation may inhibit biomass of $H$. pluvialis compared with nitrogen sufficient condition, high algal growth still could be achieved under nitrogen deficiency at high light intensities of 200, $400 \mu \mathrm{mol} / \mathrm{m}^{2} / \mathrm{s}$, which were $2.01 \pm 0.06$ and $2.19 \pm 0.08 \mathrm{~g} / \mathrm{l}$, respectively. The results suggested that the light intensity was of great significance for the algal growth and indeed increased the dry weight of biomass regardless of nitrogen starvation. Moreover, there was little difference in biomass between the two light intensities of $200 \mu \mathrm{mol} / \mathrm{m}^{2} / \mathrm{s}$ and $400 \mu \mathrm{mol} / \mathrm{m}^{2} / \mathrm{s}$, which suggested that excessive light intensity under nitrogen starvation hardly increased algal biomass. And the higher photon flux density even caused cell mortality in previous research [24]. Therefore, there is need to optimize the light intensity for selecting the optimal.

The specific growth rate is another significant index to evaluate the growth of microalgae. As shown in Table 1, the maximum specific growth rates in the initial growth stage were obtained at the highest light of $400 \mu \mathrm{mol} / \mathrm{m}^{2} / \mathrm{s}$, respectively $0.86 \pm 0.03 \mathrm{~d}^{-1}, 0.80 \pm 0.09 \mathrm{~d}^{-1}$ in nitrogen starvation and control. In this study, aeration in photobioreactors enhanced algal ability to utilize light energy and inorganic carbon, producing a slightly better growth rate than the previous best specific growth rate $\left(0.669 \mathrm{~d}^{-1}\right)$ [25]. At different light intensities, the specific growth rate in control was slightly higher than that in nitrogen deficiency, which revealed that nitrogen deficiency suppressed the growth of H. pluvialis. Similar results have been reported in previous studies, which showed the algal cell division was curbed by inhibition of cell replication due to lack of nutrition [17, $21,22]$. Therefore, the results suggested that the deficiency of nitrogen nutrient may decrease the growth of biomass.

From Table 1, it was observed that the maximal specific growth rate $\left(\mu_{\max }, \mathrm{d}^{-1}\right)$ among every group was different. The $\mu_{\max }$ in nitrogen the starvation and control groups reached $0.86 \pm 0.03 \mathrm{~d}^{-1}$ and $0.80 \pm 0.09 \mathrm{~d}^{-1}$, respectively, while the minimum of $\mu_{\max }$ value was only $0.26 \pm 0.03 \mathrm{~d}^{-1}$. Therefore, the higher specific growth rate and shorter adaptation significantly improved the average of biomass

Table 1. Growth parameters of H. pluvialis cultivation between Nitrogen Starvation and Control.

\begin{tabular}{|c|c|c|c|c|c|c|}
\hline \multicolumn{2}{|c|}{ Group $\left(\mu \mathrm{mol} / \mathrm{m}^{2} / \mathrm{s}\right)$} & \multirow{2}{*}{$\frac{\mathrm{B}_{\mathrm{o}}(\mathrm{g} / \mathrm{l})}{0.34 \pm 0.05}$} & \multirow{2}{*}{$\begin{array}{c}\mathrm{B}_{\max }(\mathrm{g} / 1) \\
1.57 \pm 0.05\end{array}$} & \multirow{2}{*}{$\begin{array}{c}\mu_{\max }\left(\mathrm{d}^{-1}\right) \\
0.26 \pm 0.03\end{array}$} & \multirow{2}{*}{$\begin{array}{c}\mathrm{BP}_{\max }(\mathrm{mg} / \mathrm{l} / \mathrm{d}) \\
156.67 \pm 15.28\end{array}$} & \multirow{2}{*}{$\begin{array}{c}\mathrm{BP}(\mathrm{mg} / \mathrm{l} / \mathrm{d}) \\
87.60 \pm 3.58\end{array}$} \\
\hline Nitrogen Starvation & 50 & & & & & \\
\hline & 100 & $0.33 \pm 0.04$ & $1.96 \pm 0.01$ & $0.52 \pm 0.13$ & $213.33 \pm 30.55$ & $115.73 \pm 7.95$ \\
\hline & 200 & $0.31 \pm 0.04$ & $2.13 \pm 0.06$ & $0.57 \pm 0.07$ & $340.33 \pm 20.10$ & $119.53 \pm 4.59$ \\
\hline & 400 & $0.32 \pm 0.06$ & $2.22 \pm 0.08$ & $0.86 \pm 0.03$ & $466.67 \pm 23.09$ & $131.90 \pm 5.98$ \\
\hline \multirow[t]{3}{*}{ Control } & 50 & $0.35 \pm 0.01$ & $1.71 \pm 0.14$ & $0.31 \pm 0.03$ & $186.67 \pm 11.55$ & $97.13 \pm 10.30$ \\
\hline & 200 & $0.31 \pm 0.01$ & $2.90 \pm 0.09$ & $0.62 \pm 0.08$ & $443.33 \pm 32.15$ & $181.93 \pm 5.77$ \\
\hline & 400 & $0.33 \pm 0.01$ & $3.43 \pm 0.06$ & $0.80 \pm 0.09$ & $643.33 \pm 40.41$ & $219.53 \pm 4.38$ \\
\hline
\end{tabular}

All measurements were performed in triplicate, and results were expressed as mean \pm standard deviation (SD). 
productivity. At the high light intensity of $200 \mu \mathrm{mol} / \mathrm{m}^{2} / \mathrm{s}$, the biomass productivity (BP) increased to $119.53 \pm 4.59$ $\mathrm{mg} / \mathrm{l} / \mathrm{d}\left(\mathrm{BP}_{\max }\right.$ of $\left.340.33 \pm 20.10\right)$ in nitrogen starvation and $181.93 \pm 5.77 \mathrm{mg} / \mathrm{l} / \mathrm{d}\left(\mathrm{BP}_{\max }\right.$ of $\left.443.33 \pm 32.15\right)$ in control group, respectively. With respect to the low light intensity of $50 \mu \mathrm{mol} / \mathrm{m}^{2} / \mathrm{s}$, the BP between nitrogen starvation and control was only $87.60 \pm 3.58 \mathrm{mg} / \mathrm{l} / \mathrm{d}\left(\mathrm{BP}_{\max }\right.$ of $156.67 \pm$ $15.28)$ and $97.13 \pm 10.30 \mathrm{mg} / \mathrm{l} / \mathrm{d}\left(\mathrm{BP}_{\max }\right.$ of $\left.186.67 \pm 11.55\right)$, respectively. These data suggested nitrogen starvation cannot dramatically decrease the biomass growth rate and productivity, especially in high light intensity. It was concluded that the biomass still increased to the desired results at the high growth rate although nitrogen starvation indeed reduced the dry weight of biomass compared to control.

\section{Astaxanthin Accumulation}

Continuous illumination was most favorable for astaxanthin accumulation in the tested illumination cycles of light and dark [26]. Moreover, many studies also described that the enhanced induction of nitrogen starvation and high light greatly improved the accumulation of astaxanthin in $H$. pluvialis [17, 23, 27-29]. The combined induction of nitrogen starvation and light intensity on astaxanthin accumulation were analyzed by comparison, including astaxanthin yield, astaxanthin content and astaxanthin production. The astaxanthin yield of $H$. pluvialis changed as shown in Fig. 2A. At the initial stage of the cultures, astaxanthin yield of all groups accumulated rapidly as the light intensity increased. Astaxanthin began to accumulate after two days of incubation, and its growth rate was faster than that in the literature [30, 31]. Astaxanthin continued accumulating rapidly under higher light intensity and reached the highest astaxanthin content, while the astaxanthin in control was in a stable stage after 11 days of cultivation at the low light intensity of 50, 100 $\mu \mathrm{mol} / \mathrm{m}^{2} / \mathrm{s}$. When the light intensity was $400 \mu \mathrm{mol} / \mathrm{m}^{2} / \mathrm{s}$, the astaxanthin yield greatly increased to $81.19 \pm 3.26$ in nitrogen starvation, and $71.40 \pm 3.11 \mathrm{mg} / \mathrm{l}$ in control on the 11th day. But then this increase was accompanied by a slight decrease that could be caused by autophagy or cell mortality rate, which was rarely presented in other papers because of shorter incubation periods or high light intensity [15, 32]. The highest astaxanthin content under nitrogen starvation was higher than those they reported [5, 15, 32-34]. Moreover, the changes in the astaxanthin content in Fig. 2B also showed similar patterns. At the high light intensity of $200,400 \mu \mathrm{mol} / \mathrm{m}^{2} / \mathrm{s}$, the astaxanthin content showed a significant increase in dry weight to 27.3
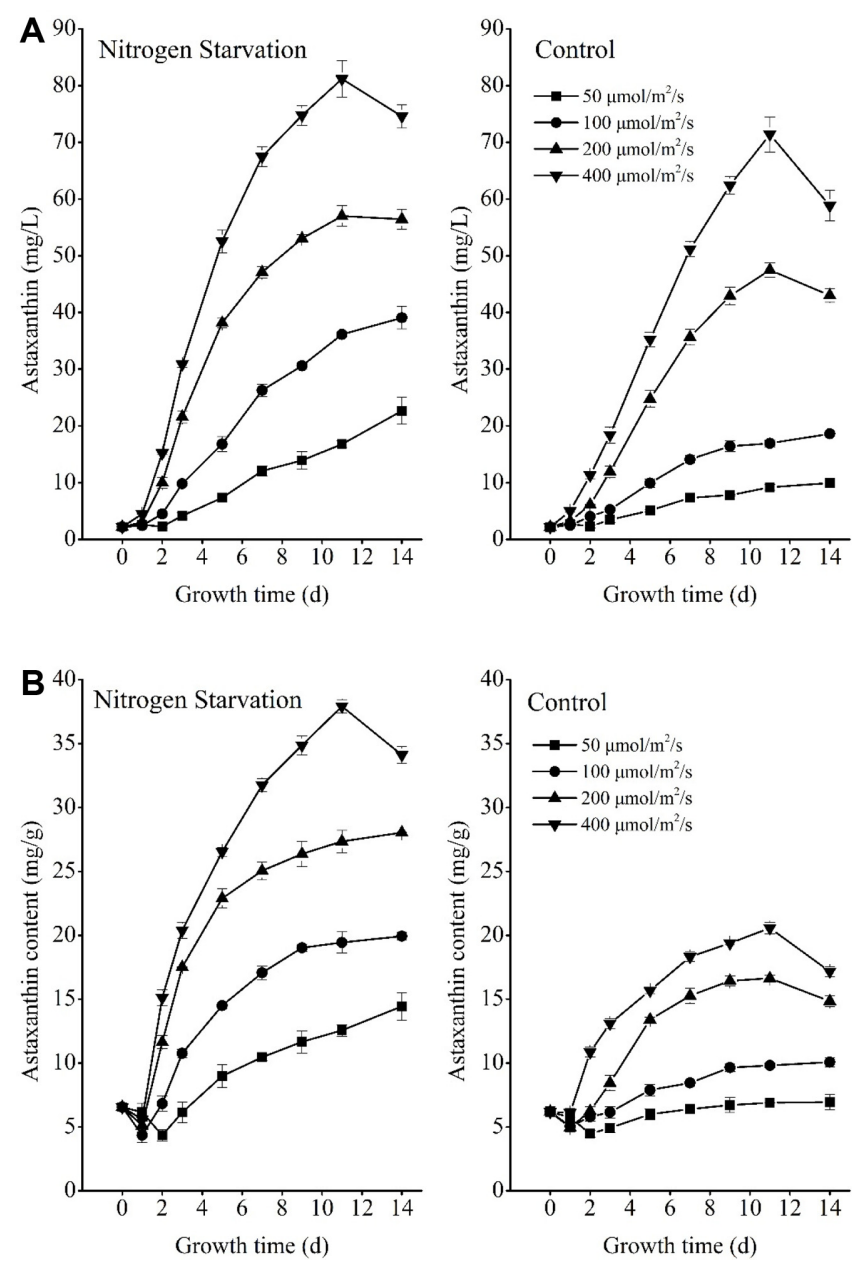

Fig. 2. Effects of different light intensities on astaxanthin yield (A), astaxanthin content of dry weight (B) between Nitrogen Starvation and Control.

and $37.9 \mathrm{mg} / \mathrm{g}$, respectively. In addition, nitrogen starvation, in particular, resulted in the highest level of astaxanthin, which was 1.64 times and 1.84 times higher than the control at 11 days. Indeed, the combination of high light and nitrogen starvation was an efficient method for accumulating high astaxanthin content, which was confirmed in the previous study [13].

Although the astaxanthin yield in nitrogen starvation was only slightly higher than that in control, the astaxanthin content in nitrogen starvation increased significantly. Especially, the astaxanthin content by dry weight under nitrogen starvation significantly increased to $37.9 \mathrm{mg} / \mathrm{g}$ at $400 \mu \mathrm{mol} / \mathrm{m}^{2} / \mathrm{s}$. The data indicated that the combination of nitrogen starvation and high light significantly induced the synthesis of astaxanthin in H. pluvialis. The previous study showed that inhibition of 

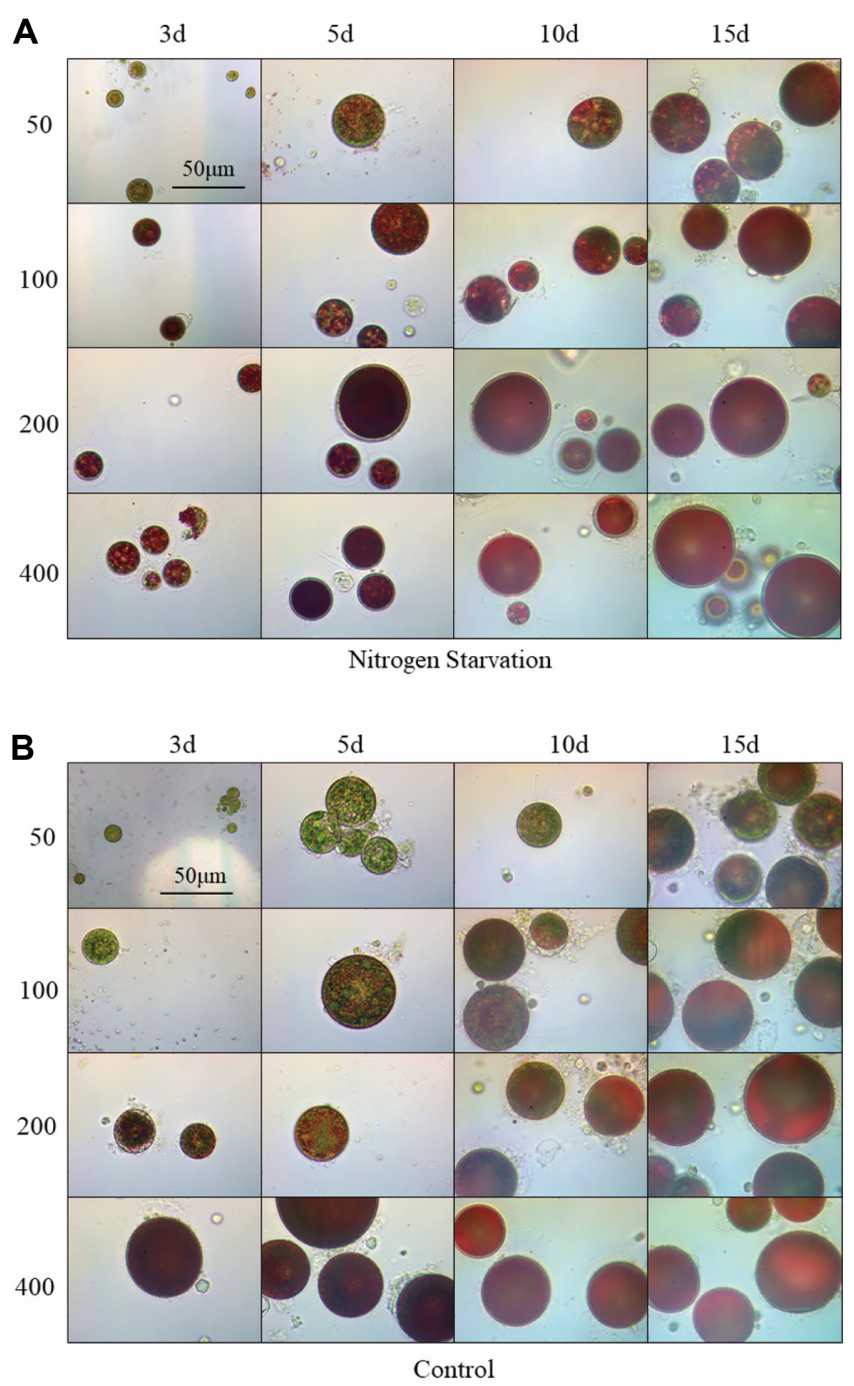

Fig. 3. Cell morphology changes under different light intensities in Nitrogen Starvation (A) and Control (B) in H. pluvialis.

autophagy by nitrogen deprivation led to a significant increase in cellular ROS levels, which contributed to the enhancement of astaxanthin accumulation [35]. Our results suggested that the inhibition under nitrogen starvation instead accumulated the astaxanthin. Although nitrogen starvation slightly reduced the biomass dry weight compared with control, which was acceptable in the microalgal market, it significantly prompted astaxanthin yield, cut costs and boosted astaxanthin productivity by shortening cultivation periods.

The microscopic variations of cell morphology changes under different light intensities for the astaxanthin accumulation of $H$. pluvialis were observed by metallographic microscope in Fig. 3. At the beginning of algal incubation, the algae were green motile cells with the cell size of 2$10 \mu \mathrm{m}$. Indeed, the astaxanthin yield was accordingly lower, only approximately $2.2-3.1 \mathrm{mg} / 1$. As shown in Fig. 3, after the cultivation for 3 days, the cell size under nitrogen starvation changed from 7-14 to $21-26 \mu \mathrm{m}$ while the size of cells in control varied from $2-7$ to $35-40 \mu \mathrm{m}$ as the light intensity increased. Besides, the cell size gradually increased as the cultivation period increased, and the overall cell size under nitrogen starvation was smaller than that of the control group. Algae cells gradually entered the cyst period and were often accompanied with flagellar shedding and volume expansion when subjected to external stress. Most motile cells induced by nitrogen starvation became larger non-motile cells with external red and internal green coloration after 5 days of incubation, and visually expressed as brown algal cells, which was consistent with the literature [30]. Then, the cells continued to proliferate at a slower rate and the volume gradually increased. At the beginning, the cells were mostly green, and then the pigment particles gradually increased, slowly spreading from the nucleus to the periphery, occupying most of the cells. Consequently, the colors of the nonmotile cells changed from brown to dark red as the cells further accumulated astaxanthin. Next, large brown coccoid cells appeared at the stationary phase at 10 days, and the size of the cells apparently changed in the range of 30-50 $\mu \mathrm{m}$, which was investigated in the report [36]. Furthermore, aplanospores rapidly transformed into deep red cysts under nitrogen starvation at high light, which was simultaneously accompanied with astaxanthin synthesis while the predominant zoospores in control under low light intensity were green or brown. At 15 days, regardless of nitrogen deficiency, the size reached $48-52 \mu \mathrm{m}$ in low light intensity and grew to as much as $66-74 \mu \mathrm{m}$ in high light intensity. Moreover, cells in nitrogen deprivation were deeper in color and bigger in size than those in control at the same light intensity. In the photobioreactors, the visual colors of $H$. pluvialis varied during the culture process as shown in the supplementary material, which accordingly reflected the astaxanthin accumulation process in macroscopic performance. Studies had shown that the accumulation of astaxanthin began at the zoospore stage $[37,38]$, which was in line with the results in this study.

\section{Light Utilization Efficiency in Astaxanthin Production}

A high content of astaxanthin was generally obtained under stress conditions, such as high light, nutrient starvation, and salinity stress [12, 13, 24, 39, 40]. But these stress conditions often caused lower microalgal growth 

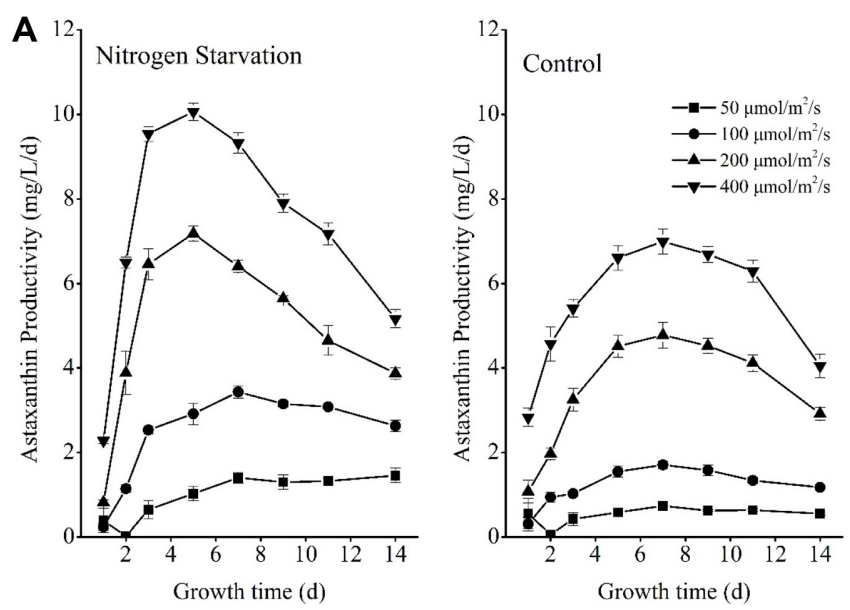

B
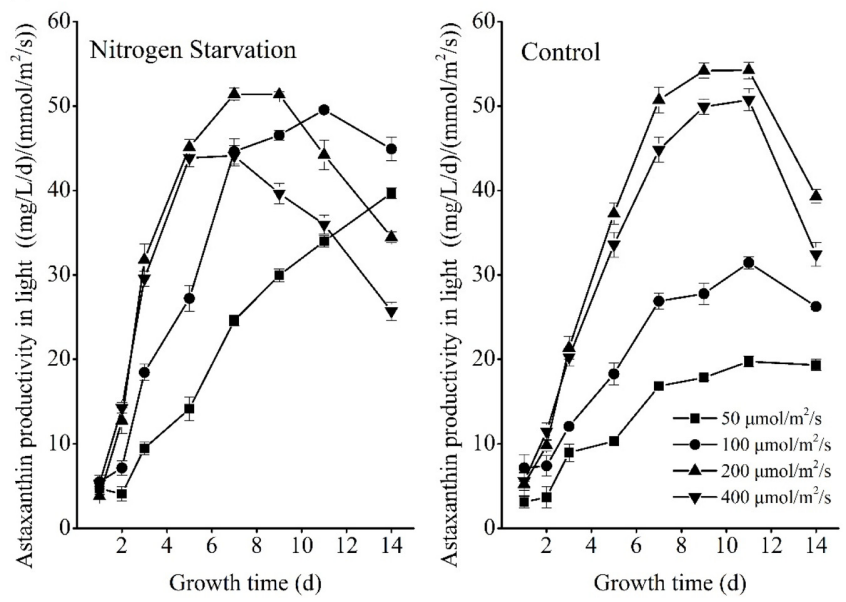

Fig. 4. Effects of different light intensities on astaxanthin productivity in H. pluvialis between Nitrogen Starvation and Control.

and poor growth rate. As such, there was a significant need to obtain higher levels of astaxanthin quality and production while simultaneously achieving high astaxanthin content. Astaxanthin productivity by dry weight in H. pluvialis rapidly increased to the maximum and then gradually declined (Fig. 4A). For the best quality astaxanthin, the biomass should be harvested at a specific culture time for the maximum productivity at day 5 (nitrogen starvation) and 7 (control). Shorter cultivation cycles also reduce contamination risks. Moreover, productivity under nitrogen starvation was significantly higher than that in control. Furthermore, the highest astaxanthin productivity had a remarkable increase of $10.06 \pm 0.21 \mathrm{mg} / \mathrm{l} / \mathrm{d}$ in nitrogen starvation and $6.70 \pm 0.30 \mathrm{mg} / \mathrm{l} / \mathrm{d}$ in control, which showed that the former was 1.50 times higher. It suggested that high light intensity and nitrogen starvation could contribute to the improvement of astaxanthin production by dry weight.

To make the best use of light energy resources, it is largely necessary to find a feasible pathway to optimize light energy utilization, trim costs and reduce energy consumption. Algal cultures with high density should be achieved by improving various cultivation methods, such as light intensity. High light intensity has the greatest impact on carotenoid accumulation. Therefore, light intensity must also be optimized and adjusted to avoid wasting light energy, especially for photoautotrophic algae. Previous studies have reported that excessive light energy cannot be absorbed or stored [41]. Besides, higher light intensity more easily caused photoinhibition growth and low light could also limit growth. Therefore, adequate light intensity and energy conservation must be simultaneously determined. The effect of light energy utilization efficiency on astaxanthin productivity was specifically evaluated in this study (Fig. 4B). Astaxanthin productivity under different light intensities showed the following trends: the changes first had a rapid increase, reached a stable stage, and then decreased. Indeed, astaxanthin productivity with light energy utilization at high light intensity rapidly peaked regardless of nitrogen deficiency. In particular at $200 \mu \mathrm{mol} / \mathrm{m}^{2} / \mathrm{s}$, astaxanthin production per light intensity quickly reached the maximum at stable growth stage, respectively 51.4 in nitrogen starvation and $54.2 \mathrm{mg} / \mathrm{l} / \mathrm{d} /\left(\mathrm{mmol} / \mathrm{m}^{2} / \mathrm{s}\right)$ in control, which were also higher than those in other light intensities. The data showed that both astaxanthin productivity and astaxanthin production per light intensity at day 7 at $200 \mu \mathrm{mol} / \mathrm{m}^{2} / \mathrm{s}$ were the highest, and thus $H$. pluvialis could make the best use of light energy to improve astaxanthin productivity. Therefore, the optimal light intensity for light energy utilization efficiency was $200 \mu \mathrm{mol} / \mathrm{m}^{2} / \mathrm{s}$, the best for obtaining higher astaxanthin production after cultivation of seven days, while avoiding wasting light energy and bringing down astaxanthin quality.

\section{Differential Response between Light Intensity and Nitrogen Starvation}

Many researchers have investigated the effects of astaxanthin accumulation stimulated by specific stress conditions, such as high light intensity and nutrient deficiency. The most important single factor related to the research on carotenogenesis was high photon-flux densities [16], and nitrogen deficiency was also reported as a major factor that hindered cell division and stimulated the synthesis of astaxanthin in other papers [42, 43]. However, 
Table 2. Differential effects between nitrogen and light by two-way analysis of variance.

\begin{tabular}{|c|c|c|c|c|c|c|}
\hline & Source & F Value & P Value & Sig. & $\mathrm{R}^{2}$ & Difference \\
\hline \multirow[t]{4}{*}{ Biomass dry weight } & Nitrogen & 306.19 & $7.43 \times 10^{-12}$ & $* * *$ & 0.984 & Nitrogen $>$ Light \\
\hline & Light & 174.47 & $1.97 \times 10^{-12}$ & $* * *$ & & \\
\hline & Interaction & 44.10 & $5.83 \times 10^{-8}$ & $* * *$ & & \\
\hline & Model & 137.41 & $4.40 \times 10^{-13}$ & $* * *$ & & \\
\hline \multirow[t]{4}{*}{ Astaxanthin yield } & Nitrogen & 283.89 & $1.32 \times 10^{-11}$ & $* * *$ & 0.992 & Nitrogen $<$ Light \\
\hline & Light & 582.94 & $1.11 \times 10^{-16}$ & $* * *$ & & \\
\hline & Interaction & 3.56 & 0.038 & $* *$ & & \\
\hline & Model & 291.91 & $1.11 \times 10^{-15}$ & $* * *$ & & \\
\hline \multirow[t]{4}{*}{ Astaxanthin content } & Nitrogen & 2392.73 & 0 & $* * *$ & 0.997 & Nitrogen $>$ Light \\
\hline & Light & 736.24 & 0 & $* * *$ & & \\
\hline & Interaction & 44.53 & $5.44 \times 10^{-8}$ & $* * *$ & & \\
\hline & Model & 676.43 & 0 & $* * *$ & & \\
\hline \multirow[t]{4}{*}{ Astaxanthin productivity } & Nitrogen & 259.07 & $2.64 \times 10^{-11}$ & $* * *$ & 0.995 & Nitrogen $<$ Light \\
\hline & Light & 1027.13 & 0 & $* * *$ & & \\
\hline & Interaction & 12.17 & $1.12 \times 10^{-4}$ & $* * *$ & & \\
\hline & Model & 482.42 & 0 & $* * *$ & & \\
\hline
\end{tabular}

$\left(p<0.01\right.$ indicating significantly different: ${ }^{* *}, p<0.05$ indicating different: ${ }^{* *}, p>0.05$ indicating not different: $\left.\mathrm{N}\right)$

All measurements were performed in triplicate, and results are expressed as mean \pm standard deviation (SD)

the differential effects of between high light intensity and nitrogen starvation have not been comprehensively explored, and were rarely reported in previous research. Since the degree of influence between light intensity and nitrogen starvation was inconsistent and even not exactly determined, further exploration was imperative for selecting optimal cultivation methods to enhance astaxanthin quality and productivity. To investigate the differences, all the samples were separately analyzed in terms of the differential effects on biomass dry weight, astaxanthin yield, astaxanthin content and astaxanthin productivity by two-way analysis of variance after cultivation for 14 days in column photobioreactors.

The evaluation parameters were the key factors for microalgal large-scale production during commercial applications. In this study, to elucidate stress-specific responses, nitrogen starvation and high light were used as single or combination stressors to induce astaxanthin accumulation. As shown in Table 2, all the analysis of variance models were very significant and the coefficient of decision was 0.984, indicating that the dry weight of biomass can be explained as $98.4 \%$ parts of light intensity, nitrogen source and interaction between the two. The analytic results showed that the biomass dry weight was significantly different between nitrogen starvation and control at different light intensities. In addition, the effects of light intensity and nitrogen on growth of biomass were significantly different $\left(F_{L}=174.47, F_{N}=306.19, p<0.01\right)$, and the interaction between them was also significant $(p<0.01)$, and the effect of a nitrogen source on the growth of biomass was greater than that of light intensity. Given the research analysis in all the groups, it was concluded that sufficient nitrogen was more important than light intensity for algal growth. However, the different effects largely varied on the astaxanthin yield and astaxanthin content. The astaxanthin content clearly varied resulting in a great gap when the yield of astaxanthin under nitrogen starvation was slightly higher than that in control under different light intensities. Especially, the difference of the astaxanthin content in dry weight was highly significant. For the variance analysis, the two model explanation parts of astaxanthin yield and astaxanthin content were respectively $99.2 \%$ and $99.7 \%$. Indeed, both light intensity and nitrogen source had important effects on astaxanthin yield and astaxanthin content in dry weight, and the interaction between them was significant. But the differential effects on astaxanthin yield and astaxanthin content in this study were completely different. Considering the experimental results, especially, the astaxanthin content was as high as $71.4 \mathrm{mg} / 1$ at $400 \mu \mathrm{mol} / \mathrm{m}^{2} / \mathrm{s}$, which was 7.76 -fold higher than the minimum of $9.20 \mathrm{mg} / 1$ in control at $50 \mu \mathrm{mol} / \mathrm{m}^{2} / \mathrm{s}$. Statistical analysis showed that light intensity had much more significant influence than nitrogen source on the astaxanthin yield. On the contrary, 
the effect of light intensity was less significant than a nitrogen source on astaxanthin content by dry weight. Therefore, nitrogen starvation treatment was more beneficial for improving the quality. Besides, astaxanthin productivity is one of the important factors in astaxanthin production. As a result, the influences of light intensity on astaxanthin productivity were dramatically stronger than that of a nitrogen source.

Although the influence of nitrogen was much more obvious than that of light intensity, nitrogen starvation inhibited the growth of biomass dry weight, which indicated that light intensity had more advantages for biomass. The analysis also showed that the effects of light intensity on astaxanthin yield and productivity were greater than that of nitrogen, which implied that regulation of light intensity would play a more important role than nitrogen starvation for astaxanthin yield and productivity. Moreover, the effect of nitrogen starvation on astaxanthin content was almost twice as high as that of light intensity. In the present study, we concluded that appropriate high light intensity would be a better approach to produce high biomass, astaxanthin yield and astaxanthin productivity, and nitrogen starvation was better for astaxanthin content during shorter cultivation periods. Therefore, it was clear that light intensity had higher significant effects on the biomass dry weight, astaxanthin yield and astaxanthin productivity, while nitrogen starvation may be a favorable strategy for rapidly accelerating astaxanthin content.

\section{Acknowledgments}

This research was financially supported by the Major Science and Technology Program for Water Pollution Control and Treatment (2015ZX07402003-5) of China and the National Natural Science Foundation of China (No. 51778448, 41671488).

\section{Conflict of Interest}

The authors have no financial conflicts of interest to declare.

\section{References}

1. Borowitzka MA. 2013. High-value products from microalgaetheir development and commercialisation. J. Appl. Phycol. 25: 743-756.

2. Koller M, Muhr A, Braunegg G. 2014. Microalgae as versatile cellular factories for valued products. Algal. Res. 6: 52-63.

3. Perez-Lopez P, Gonzalez-Garcia S, Jeffryes C, Agathos SN,
McHugh E, Walsh D, et al. 2014. Life cycle assessment of the production of the red antioxidant carotenoid astaxanthin by microalgae: from lab to pilot scale. J. Clean. Prod. 64: 332-344.

4. Lorenz RT, Cysewski GR. 2000. Commercial potential for Haematococcus microalgae as a natural source of astaxanthin. Trends Biotechnol. 18: 160-167.

5. Wan MX, Hou DM, Li YG, Fan JH, Huang JK, Liang ST, et al. 2014. The effective photoinduction of Haematococcus pluvialis for accumulating astaxanthin with attached cultivation. Bioresour. Technol. 163: 26-32.

6. Sammy B, Wang B, Jian-Ping Y, Aliza Z, Feng C. 1999. Changes in pigments profile in the green alga Haeamtococcus pluvialis exposed to environmental stresses. Bioresour. Technol. 21: 601-604.

7. Li Y, Sommerfeld M, Chen F, Hu Q. 2008. Consumption of oxygen by astaxanthin biosynthesis: a protective mechanism against oxidative stress in Haematococcus pluvialis (Chlorophyceae). J. Plant. Physiol. 165: 1783-1797.

8. Li YT, Sommerfeld M, Chen F, Hu Q. 2010. Effect of photon flux densities on regulation of carotenogenesis and cell viability of Haematococcus pluvialis (Chlorophyceae). J. Appl. Phycol. 22: 253-263.

9. Kang CD, Lee JS, Park TH, Sim SJ. 2007. Complementary limiting factors of astaxanthin synthesis during photoautotrophic induction of Haematococcus pluvialis: $\mathrm{C} / \mathrm{N}$ ratio and light intensity. Appl. Microbiol. Biotechnol. 74: 987-94.

10. Tan XB, Zhao XC, Zhang YL, Zhou YY, Yang LB, Zhang WW. 2018. Enhanced lipid and biomass production using alcohol wastewater as carbon source for Chlorella pyrenoidosa cultivation in anaerobically digested starch wastewater in outdoors. Bioresour. Technol. 247: 784-793.

11. Boussiba S, Fan L, Vonshak A. 1992. Enhancement and determination of astaxanthin accumulation in green-alga Haematococcus-Plubialis. Methods Enzymol. 213: 386-391.

12. Kiperstok AC, Sebestyen P, Podola B, Melkonian M. 2017. Biofilm cultivation of Haematococcus pluvialis enables a highly productive one-phase process for astaxanthin production using high light intensities. Algal Res. 21: 213-222.

13. Scibilia L, Girolomoni L, Berteotti S, Alboresi A, M B. 2015. Photosynthetic response to nitrogen starvation and high light in Haematococcus pluvialis. Algal Res. 12: 170-181.

14. Katsuda T, Shimahara K, Shiraishi H, Yamagami K, Ranjbar R, Katoh S. 2006. Effect of flashing light from blue light emitting diodes on cell growth and astaxanthin production of Haematococcus pluvialis. J. Biosci. Bioeng. 102: 442-446.

15. Zhang CH, Zhang LT, Liu JG. 2016. The role of photorespiration during astaxanthin accumulation in Haematococcus pluvialis (Chlorophyceae). Plant Physiol. Biochem. 107: 75-81.

16. Harker M, Tsavalos AJ, Young AJ. 1996. Factors responsible for astaxanthin formation in the chlorophyte Haematococcus pluvialis. Bioresour. Technol. 55: 207-214.

17. Cakmak T, Angun P, Demiray YE, Ozkan AD, Elibol Z, Tekinay T. 2012. Differential effects of nitrogen and sulfur 
deprivation on growth and biodiesel feedstock production of Chlamydomonas reinhardtii. Biotechnol. Bioeng. 109: 1947-1957.

18. Fábregas J, Domínguez A, Álvarez DG, Lamela T, AO. 1998. Induction of astaxanthin accumulation by nitrogen and magnesium deficiencies in Haematococcus pluvialis. Biotechnol. Lett. 20: 623-626.

19. Borowitzka MA, Huisman JM, Osborn A. 1991. Culture of the astaxanthin-producing green-alga Haematococcus-Pluvialis. 1. Effects of nutrients on growth and cell type. J. Appl. Phycol. 3: 295-304.

20. Berges JA, Charlebois DO, Mauzerall DC, Falkowski PG. 1996. Differential effects of nitrogen limitation on photosynthetic efficiency of photosystems I and II in microalgae. Plant Physiol. 110: 689-696.

21. Dong HP, Williams E, Wang DZ, Xie ZX, Hsia RC, Jenck A, et al. 2013. Responses of Nannochloropsis oceanica IMET1 to long-term nitrogen starvation and recovery. Plant Physiol. 162: $1110-1126$.

22. Hockin NL, Mock T, Mulholland F, Kopriva S, Malin G. 2012. The response of diatom central carbon metabolism to nitrogen starvation is different from that of green algae and higher plants. Plant Physiol. 158: 299-312.

23. Scibilia L, Girolomoni L, Berteotti S, Alboresi A, Ballottari M. 2015. Photosynthetic response to nitrogen starvation and high light in Haematococcus pluvialis. Algal Res. 12: 170-181.

24. Li Y, Sommerfeld M, Chen F, Hu Q. 2010. Effect of photon flux densities on regulation of carotenogenesis and cell viability of Haematococcus pluvialis (Chlorophyceae). J. Appl. Phycol. 22: 253-263.

25. Sun H, Liu B, Lu X, Cheng KW, Chen F. 2017. Staged cultivation enhances biomass accumulation in the green growth phase of Haematococcus pluvialis. Bioresour. Technol. 233: 326-331.

26. Kobayashi M, Kakizono T, Nishio N, S N. 1992. Effects of light intensity, light quality, and illumination cycle on astaxanthin formation in a green alga, Haematococcus pluvialis. J. Ferment. Bioeng. 74: 61-63.

27. Mao XM, Wu T, Sun DZ, Zhang Z, Chen F. 2018. Differential responses of the green microalga Chlorella zofingiensis to the starvation of various nutrients for oil and astaxanthin production. Bioresour. Technol. 249: 791-798.

28. Recht L, Zarka A, Boussiba S. 2012. Patterns of carbohydrate and fatty acid changes under nitrogen starvation in the microalgae Haematococcus pluvialis and Nannochloropsis sp. Appl. Microbiol. Biotechnol. 94: 1495-1503.

29. Fabregas J, Dominguez A, Maseda A, Otero A. 2003. Interactions between irradiance and nutrient availability during astaxanthin accumulation and degradation in Haematococcus pluvialis. Appl. Microbiol. Biotechnol. 61: 545-551.

30. Zhang LT, Su F, Zhang CH, Gong FY, Liu JG. 2017. Changes of photosynthetic behaviors and photoprotection during cell transformation and astaxanthin accumulation in Haematococcus pluvialis grown outdoors in tubular photobioreactors. Int. J. Mol. Sci. 18: 33.

31. Kim ZH, Park H, Lee HS, Lee CG. 2016. Enhancing photon utilization efficiency for astaxanthin production from Haematococcus lacustris using a split-column photobioreactor. J. Microbiol. Biotechnol. 26: 1285-1289.

32. Cheng J, Li K, Yang ZB, Zhou JH, Cen KF. 2016. Enhancing the growth rate and astaxanthin yield of Haematococcus pluvialis by nuclear irradiation and high concentration of carbon dioxide stress. Bioresour. Technol. 204: 49-54.

33. Zhang Z, Wang BB, Hu Q, Sommerfeld M, Li YG, Han DX. 2016. A new paradigm for producing astaxanthin from the unicellular green alga Haematococcus pluvialis. Biotechnol. Bioeng. 113: 2088-2099.

34. Christian D, Zhang J, Sawdon AJ, Peng CA. 2018. Enhanced astaxanthin accumulation in Haematococcus pluvialis using high carbon dioxide concentration and light illumination. Bioresour. Technol. 256: 548-551.

35. Zhang Z, Sun DZ, Cheng KW, Chen F. 2018. Inhibition of autophagy modulates astaxanthin and total fatty acid biosynthesis in Chlorella zofingiensis under nitrogen starvation. Bioresour. Technol. 247: 610-615.

36. Chekanov K, Lukyanov A, Boussiba S, Aflalo C, Solovchenko A. 2016. Modulation of photosynthetic activity and photoprotection in Haematococcus pluvialis cells during their conversion into haematocysts and back. Photosynth. Res. 128: 313-323.

37. Santos MF, Mesquita JF. 1984. Ultrastructural-study of Haematococcus-Lacustris (Girod) Rostafinski (Volvocales) .1. Some aspects of carotenogenesis. Cytologia 49: 215-228.

38. Zhuang H, Lu H, W. C. 1999. Ultrastructural study on the process of astaxanthin accumulation in Haematococcus pluvialis Flotow under stress condition. J. Chine. Elect. Microsc. Soc. 19: $137-142$.

39. S B. 2000. Carotenongenesis in green alga Haematococcus pluvialis: Cellular physiology and response stress. Physiol. Plantarum. 108: 111-117.

40. Zhekisheva M, Boussiba S, Khozin-Goldberg I, Zarka A, Cohen Z. 2002. Accumulation of oleic acid in Haematococcus pluvialis (Chlorophyceae) under nitrogen starvation or high light is correlated with that of astaxanthin esters. J. Phycol. 38: 325-331.

41. Wichuk K, Brynjolfsson S, Fu W. 2014. Biotechnological production of value-added carotenoids from microalgae: emerging technology and prospects. Bioengineered. 5: 204-208.

42. Borowitzka M A HJM, Osborn A. 1991. Culture of the astaxanthin-producing green alga Haematococcus pluvialis 1 . Effects of nutrients on growth and cell type. J. Appl. Phycol. 3: 295-304.

43. Fabregas J, Dominguez A, Alvarez DG, Lamela T, Otero A. 1998. Induction of astaxanthin accumulation by nitrogen and magnesium deficiencies in Haematococcus pluvialis. Biotechnol. Lett. 20: 623-626. 